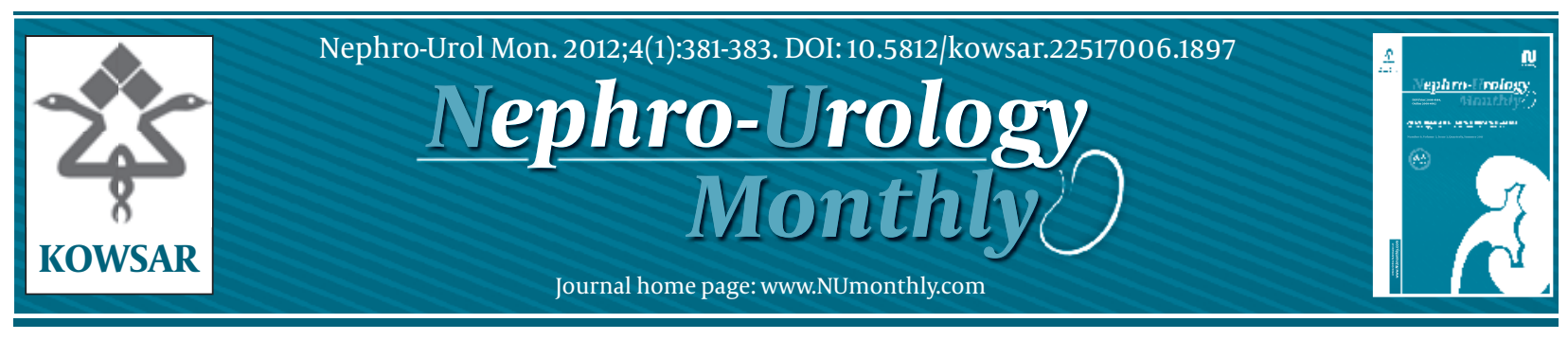

\title{
Radical Nephrectomy in a 96-year-old Man With Chromophobe Renal Cell Carcinoma Presenting With Huge Hemorrhagic Cyst Formation: A Case Report
}

\author{
Mohammad Hossein Nourbala ${ }^{1}$, Ali Momenzadeh ${ }^{1}$, Amin Saburi ${ }^{2}$, Zeinab Telkabadi ${ }^{1}$ \\ ${ }^{1}$ Nephrology and Urology Research Center, Baqiyatallah University of Medical Sciences, Tehran, IR Iran \\ ${ }^{2}$ Health Research Center, Baqiyatallah University of Medical Sciences, Tehran, IR Iran
}

\begin{tabular}{|c|c|}
\hline A R T I C L E I N F O & A B S T R A C T \\
\hline $\begin{array}{l}\text { Article type: } \\
\text { Case Report }\end{array}$ & $\begin{array}{l}\text { Chromophobe renal cell carcinoma (CRCC) is an uncommon RCC, and its clinical fea- } \\
\text { tures are different than those of other RCCs. We report the case of a } 96 \text {-year-old male }\end{array}$ \\
\hline Article history: & $\begin{array}{l}\text { patient who was diagnosed with CRCC presenting with a huge hemorrhagic cyst that } \\
\text { was successfully excised via open surgery without any complication. The occurrence of }\end{array}$ \\
\hline Received: 22 Jul 2011 & a hemorrhagic cyst in a male CRCC patient of advanced age is extremely rare. Because \\
\hline Revised: 07 Aug 2011 & CRCC is less fatal than other RCC subtypes, the former frequently present with extended \\
\hline Accepted: 18 Aug 2011 & and spacious features. Although safe and effective, operation is an uncommon approach \\
\hline
\end{tabular}

Keywords:

Carcinoma, Renal Cell

Cysts

Nephrectomy

Copyright $\odot 2012$, Kowsar M.P.Co. All rights reserved.

- Implication for health policy/practice/research/medical education:

We report the case of a 96-year-old male patient who was diagnosed with CRCC presenting with a huge hemorrhagic cyst that was successfully excised via open surgery without any complication. Also safety and effective of the Radical Nephrectomy in patient with co-morbidity, such as that in our patient was discussed in this paper.

- Please cite this paper as:

Nourbala MH, Momenzadeh A, Saburi A, Telkabadi Z. Radical Nephrectomy in a 96-year-old Man With Chromophobe Renal Cell Carcinoma Presented With Huge Hemorrhagic Cyst Formation: A Case Report. Nephro-Urol Mon.2012;4(1):381-3.

DOI: $10.5812 /$ kowsar.22517006.1897

\section{Background}

Renal cell carcinoma (RCC) is one of the most common neoplasms affecting adults, and its incidence is estimated to be between $3 \%$ and $4 \%$ of new cancer cases in the United States (1). RCC is generally detected in the fifth to seventh decade of life, with the median age at diagnosis being 60 years and the median age at death being 70 years (2). Tumor size is usually between 4 and $7 \mathrm{~cm}$, but it can range from a few millimeters to sufficiently large to

* Corresponding author: Amin Saburi, Health Research Center, Baqiyatallah University of Medical Sciences, Tehran, IRIran. Tel/Fax:+98-2188040060, E-mail:aminsaburi@yahoo.com

DOI:10.5812/kowsar.22517006.1897

Copyright $\odot 2012$, Kowsar M.P.Co. All rights reserved. fill the entire abdominal cavity $(3,4)$.

Tumors may be solid, cystic, or mixed, containing excess fat and calcified tissue. Of all RCCs, $4 \%$ to $10 \%$ have the cystic component $(5,6)$. According to the Heidelberg classification, the histological subtypes of RCC include carcinoma containing clear cells (conventional RCC), papillary RCC, chromophobe RCC (CRCC), collecting duct carcinoma, and unclassified carcinoma $(7,8)$. These subtypes vary in their cytogenetic and immunohistochemical properties and have different prognoses.

CRCC is an uncommon subtype of RCC that accounts for $1.8 \%$ of RCCs, the age-standardized incidence rate being 0.17/100 000 per year (9). The clinical behavior of CRCC has not yet been adequately defined, though most studies suggest that CRCC has a better prognosis than 
conventional RCC (3). The more favorable survival of the CRCC subtype seems to be described by these neoplasms being diagnosed at low stages. Diagnosis of the neoplasm at an early stage appears to increase the survival of CRCC patients. . Previous reports have suggested that CRCC tends to remain localized and is maintained in a predominantly low-grade condition in spite of its gradual growth. (9). We present the case of a 96-year-old man with CRCC presenting with a huge hemorrhagic cyst that was successfully excised via open surgery without any complication.

\section{Case Presentation}

A 96-year-old male patient was admitted to our hospital presenting with progressive fatigue, loss of appetite, and weight loss of approximately $10 \mathrm{~kg}$ over the previous 5 months. He had no remarkable medical history; however, he was a smoker (40 pack/years [ amount of cigarette packs which used per day / Years that the patient stays on smoker]). Physical examination revealed a huge and palpable abdominal mass without tenderness and without any other significant finding. In laboratory tests, anemia $(\mathrm{Hb}, 9.7 \mathrm{~g} / \mathrm{dL}$ ) and microhematuria were found as the sole abnormal findings in urine and blood sample analyses. Ultrasonography (US) showed a homogenous giant mass in the left kidney. Computed tomography (CT) scan revealed a retroperitoneal left renal cyst with enhanced solid components that occupied most of the abdominal and pelvic spaces (Figure 1).

The patient had undergone radical nephrectomy (RN) on the left side. We applied the extraperitoneal left flank surgical approach (because of our preference and experience), and the total surgery time was $1 \mathrm{~h}$. The renal cyst contained $5.5 \mathrm{~L}$ of red-brown liquid which appeared to be old blood. Regarding the cyst size and instability of the cyst wall, there was a possibility that the cyst could split and its contents would leak into the abdominal cavity. Therefore, the surgeons did not take a risk, and first extracted the cyst contents by suction while monitoring the patient's hemodynamic status. Subsequently, the adhesions around the cyst were dissected carefully, and finally a large solid mass was visible in the left renal hilum. Renal vessels and ureters were clamped and dissected separately.

Further, we found a large firm para-aortic lymph node that was retained because it was fixed to the main abdominal vessels. The size of the renal cyst was reported as $27 \mathrm{~cm} \times 20 \mathrm{~cm} \times 5 \mathrm{~cm}$ and the solid component diameter was $14 \mathrm{~cm}$ (Figure 2). Furthermore, the parts of the cyst wall were covered with necrotic tumor tissue. The patient was examined to detect metastasis to the suspicious area. Chest radiography showed no evidence of metastasis; other workups such as liver function tests, including transaminase and alkaline phosphatase levels, serum calcium and phosphorus levels, and abdominal computed tomography did not indicate metastasis to the liver and bone. The results of pathological analysis confirmed RCC (chromophobe type) with invasion to perinephric fat. Tumor staging according to the tumornode-metastasis (TNM) system was stage 3 (pT3aN1M0).
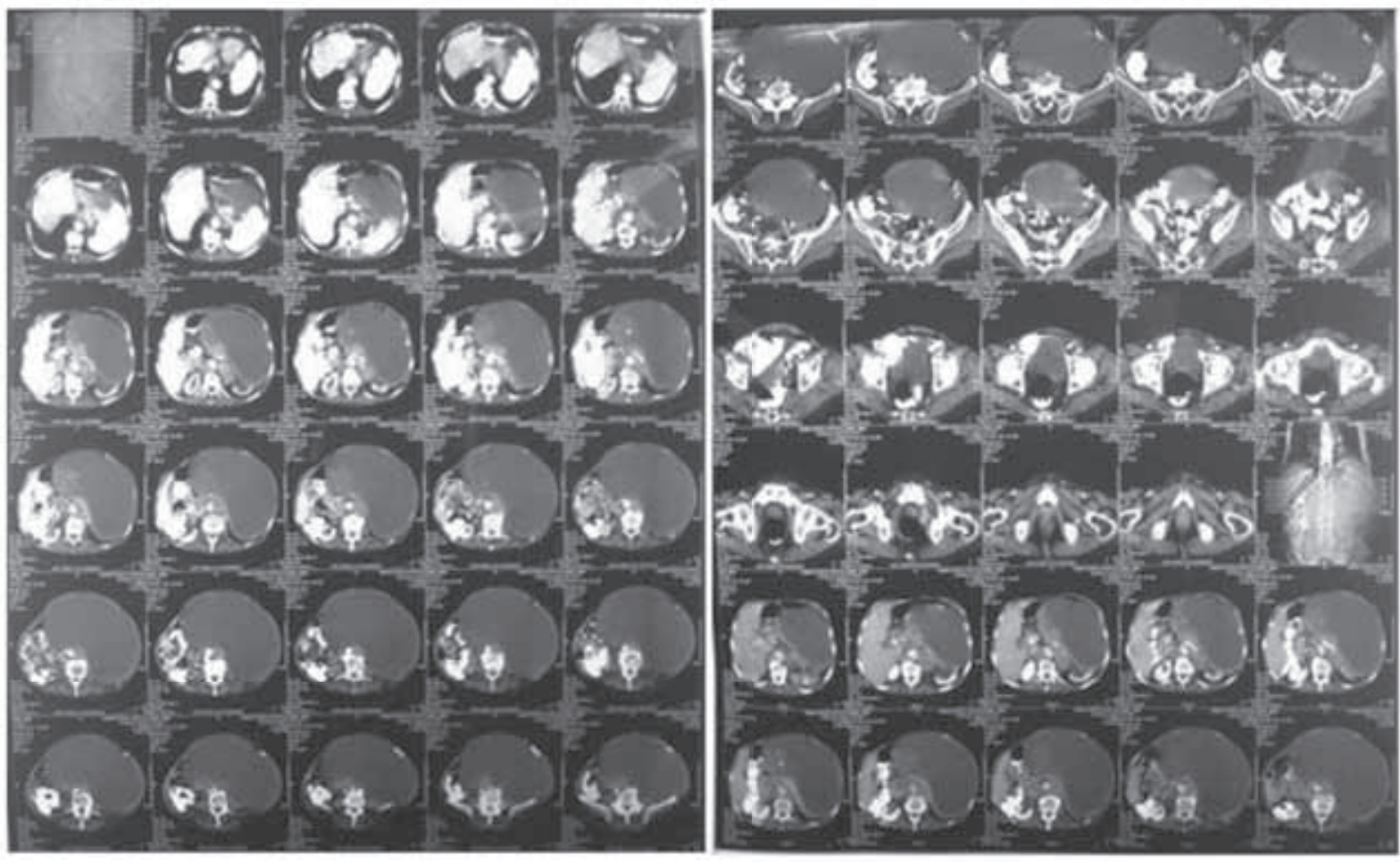

Figure 1. CT Scan Revealed a Giant Renal Cyst With an Enhanced Solid Component Occupying the Abdominal and Pelvic Cavity. 


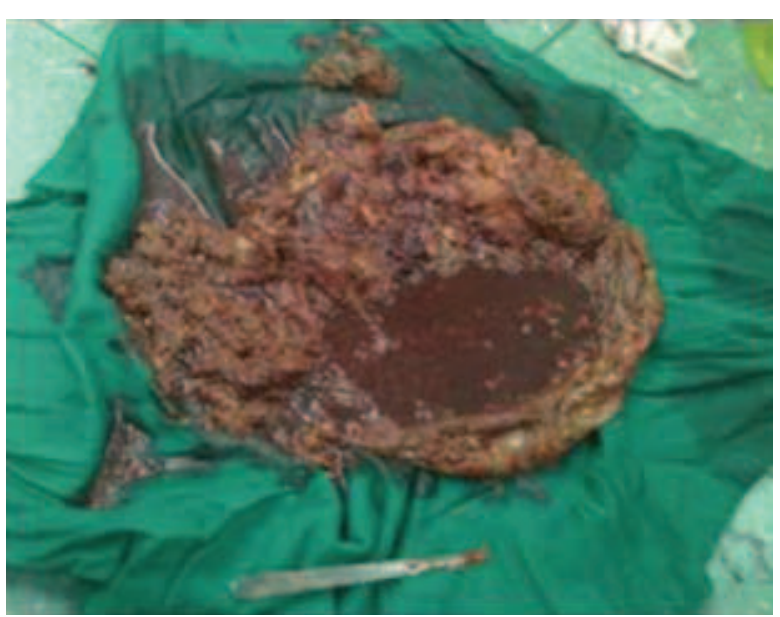

Figure 2. Renal Cyst After RN Showing Cystic and Solid Components Filled With 5.5 L of Red-brown Material Which Appears to Be Old Blood Clots. (Cystic Mass Opened by Surgeon for Examination).

Histological grade was reported as grade 2. The patient was discharged from the hospital in good general condition 4 days later, and subsequently referred to an oncologist for chemotherapy. At the last visit after 2 months, the patient's general condition was stable without any operation-related complications.

\section{Discussion}

RN in RCC patients with advanced age, poor performance status, and a huge renal mass, accompanied by technical difficulties, is a challenging procedure (10). However, loss of appetite and progressive weight loss due to a huge cystic mass necessitated a palliative and cytoreductive RN.

There are some noteworthy points in our case, e.g., a giant mass occupied the abdominal and pelvic spaces. Further, the tumor presentation of this size in a 96-year-old patient has been reported infrequently and CRCC with huge hemorrhagic cyst formation is rare. RN in high-risk patients, such as that in our patient, is an uninterested approach. Several surgical approaches are available for $\mathrm{RN}$, which are selected according to the surgeons' experience and preference. The flank approach in patients with very large mass, such as in the present case, could be beneficial to assess vessels and facilitate their ligation. Adachi et al. reported the case of a very young patient with RCC characterized by small hemorrhagic cyst formation, which was treated with RN (11). CRCC is commonly presented during its early stages, and the presentation of a late-stage CRCC with a huge kidney cyst is very rare $(9,12)$. Furthermore, it appears that the prevalence of the chromophobic type of RCC in the Iranian population is lower than its global estimated prevalence (13). Although therapeutic protocols are selected according to the patient's condition, $\mathrm{RN}$ is a risky and challenging surgery for RCC in patients with a comorbidity such as old age (over 75 years old) or concomitant complications $(14,15)$. The favorable results obtained in this case suggest that $\mathrm{RN}$ is a safe and effective option for very old patients with giant renal tumor.

\section{Acknowledgments}

The authors thank the patient and her family for their kind collaboration.

\section{Financial Disclosure}

None declared.

\section{Funding/Support}

None declared.

\section{References}

1. Jemal A, Siegel R, Ward E, Murray T, Xu J, Thun MJ. Cancer statistics, 2007. CA Cancer J Clin. 2007;57(1):43-66.

2. Nemeth I, Sukosd F, Beli L, Kiss A, Pajor L, Miko T, et al. [Adult renal neoplasms in the material of the Pathology Department of the Szeged University]. Orv Hetil. 2005;146(14):653-8.

3. Amin MB, Tamboli P, Javidan J, Stricker H, de-Peralta Venturina $\mathrm{M}$, Deshpande A, et al. Prognostic impact of histologic subtyping of adult renal epithelial neoplasms: an experience of 405 cases. Am J Surg Pathol. 2002;26(3):281-91.

4. Wang H, Cheng L, Zhang X, Wang D, Guo A, Gao Y, et al. Renal cell carcinoma: diffusion-weighted MR imaging for subtype differentiation at 3.0 T. Radiology. 2010;257(1):135-43.

5. Corica FA, Iczkowski KA, Cheng L, Zincke H, Blute ML, Wendel A, et al. Cystic renal cell carcinoma is cured by resection: a study of 24 cases with long-term followup.J Urol. 1999;161(2):408-11.

6. Aubert S, Zini L, Delomez J, Biserte J, Lemaitre L, Leroy X. Cystic renal cell carcinomas in adults. Is preoperative recognition of multilocular cystic renal cell carcinoma possible? J Urol. 2005;174(6):2115-9.

7. Kovacs G, Akhtar M, Beckwith BJ, Bugert P, Cooper CS, Delahunt B, et al. The Heidelberg classification of renal cell tumours. $J$ Pathol.1997;183(2):131-3.

8. Bostwick DG, Eble JN. Diagnosis and classification of renal cell carcinoma. Urol Clin North Am. 1999;26(3):627-35.

9. Ingimarsson JP, Hardarson S, Petursdottir V, Jonsson E, Einarsson GV, Gudbjartsson T. Chromophobe renal cell carcinoma in Iceland: An epidemiological and clinicopathological study. Scand J Urol Nephrol. 2011;45(5):306-11.

10. Santos Arrontes D, Fernandez Acenero MJ, Garcia Gonzalez JI, Martin Munoz M, Paniagua Andres P. Survival analysis of clear cell renal carcinoma according to the Charlson comorbidity index.J Urol. 2008;179(3):857-61.

11. Adachi T, Nakatani T, Minami H, Ikemoto S, Esaki K, Morimoto H, et al. Renal cell carcinoma with hemorrhagic cyst formation in a 4-year-old boy. Int J Urol. 2003;10(5):267-70.

12. Klatte T, Han KR, Said JW, Bohm M, Allhoff EP, Kabbinavar FF, et al. Pathobiology and prognosis of chromophobe renal cell carcinoma. Urol Oncol. 2008;26(6):604-9.

13. Tabibi A, Parvin M, Abdi H, Bashtar R, Zamani N, Abadpour B. Correlation between size of renal cell carcinoma and its grade, stage, and histological subtype. Urol J. 2007;4(1):10-3.

14. Casella R, Ferrier C, Giudici G, Dickenmann M, Giannini O, Hosli I, et al. Surgical management of renal cell carcinoma during the second trimester of pregnancy. Urol Int. 2006;76(2):180-1.

15. Lane BR, Abouassaly R, Gao T, Weight CJ, Hernandez AV, Larson $\mathrm{BT}$, et al. Active treatment of localized renal tumors may not impact overall survival in patients aged 75 years or older. Cancer. 2010;116(13):3119-26. 